
\title{
$\begin{array}{ll}\text { Research Square } & \begin{array}{l}\text { Preprints are preliminary reports that have not undergone peer review. } \\ \text { They should not be considered conclusive, used to inform clinical practice, } \\ \text { or referenced by the media as validated information. }\end{array}\end{array}$
}

\section{Support for Lowering Cervical Cancer Screening Age To 25 for Women Living With HIV: Retrospective Cross-Sectional Programmatic Data From Botswana}

\author{
Doreen Ramogola-Masire ( $\nabla$ doreen.masire@gmail.com ) \\ University of Botswana \\ Surbhi Grover \\ Botswana U-Penn Partnership \\ Anikie Mathoma \\ University of Botswana \\ Barati Monare \\ Botswana U-Penn Partnership \\ Lesego Gabaitiri \\ University of Botswana \\ Lisa Bazzett-Matabele \\ University of Botswana \\ G Justus Hofmeyr \\ University of Botswana \\ Chelsea Morroni \\ Botswana-Harvard AIDS Institute Partnership \\ Rebecca Luckett \\ University of Botswana
}

\section{Research Article}

Keywords: Botswana, Cervical pre-cancer, Cervical cancer screening, Colposcopy, Cryotherapy, Loop electrical excision procedure, See-andtreat, Visual inspection after acetic acid

Posted Date: September 23rd, 2021

DOI: https://doi.org/10.21203/rs.3.rs-842341/v1

License: (c) (1) This work is licensed under a Creative Commons Attribution 4.0 International License. Read Full License

Version of Record: A version of this preprint was published at BMC Women's Health on April 2nd, 2022. See the published version at https://doi.org/10.1186/s12905-022-01680-7. 


\section{Abstract}

\section{Background:}

Women living with human immunodeficiency virus (HIV) tend to develop cervical cancer at a younger age than HIV-negative women. The World Health Organization's (WHO) new guidelines for screening and treatment of cervical pre-cancer lesions for cervical cancer prevention include a conditional recommendation for initiating screening at age 25 for women living with HIV (WLWH). This recommendation is based on low-certainty evidence, and WHO calls for additional data. We describe the association of age and HIV status with visual inspection with acetic acid (VIA) positivity and cervical intra-epithelial neoplasia grade two or higher (CIN2+) in Botswana.

\section{Methods:}

A retrospective cross-sectional study of 5,714 participants aged 25 through 49 years who underwent VIA screening. VIA-positive women received cryotherapy if indicated or were referred for colposcopy. Known cervical cancer risk factors, screening, and histological results were extracted from the program database. We compared the proportions and association of VIA positivity and CIN2+ by age and HIV status.

\section{Results:}

Median age was 35 years [IQR 31-39], and 18\% of the women were aged 25-29. Ninety percent were WLWH; median CD4 count was 250 cells/ $\mu \mathrm{L}$ [IQR 150-428], and 34.2\% were on anti-retroviral treatment (ART). VIA-positivity was associated with younger age (OR 1.48, Cl 1.28, 1.72 for 25-29 years versus age 30-49 years ), and HIV-positivity (OR 1.85, Cl 1.51, 2.28). CIN2+ was associated with HIV positivity (OR $6.12, \mathrm{Cl} 3.39,11.10)$, and proportions of CIN2+ were similar for both age groups in WLWH (12.1\% versus $10.8 \%)$.

\section{Conclusions:}

Younger WLWH in Botswana had a significant burden of CIN2+. This finding further supports lowering the screening age for WLWH from 30 to 25 .

\section{Background}

Low- and middle-income countries (LMICs) carry the highest global burden of cervical cancer incidence and mortality.[1] Cervical cancer is the leading cause of cancer death in women in Southern Africa. [2,3] While human papillomavirus (HPV) vaccination in young girls offers hope for a significant reduction in cervical cancer in future generations, effective cervical cancer screening services remain essential to reduce morbidity and mortality associated with cervical cancer in women across the globe.[4]

Women living with the human immunodeficiency virus (WLWH) have a higher risk of developing pre-invasive cervical disease and cervical cancer.[5-7] Although progression rates from pre-invasive cervical disease to cervical cancer are unknown due to standard intervention for high-grade cervical dysplasia, cervical cancer is diagnosed at younger ages in WLWH compared to HIV-negative women. [5, 8, 9] Guidelines for high-income countries (HICs) recommend cervical cancer screening initiation at an early age of 21.[10-12] Up till recently, guidelines for most LMICs recommended the initiation of cervical cancer screening at the age of 30 despite LMICs having the highest global prevalence of HIV in the reproductive-aged population. $[13,14]$. The new WHO guidelines have a conditional recommendation based on low-certainty evidence for initiating screening at age 25 for WLWH, [15] and calls for more data. Further, many LMICs will not be able to change their guidelines straight away due to resource constraints.

Botswana has one of the highest HIV prevalences globally, at 25.1\% in women aged 15-49.[16] Botswana's national guidelines prioritize screening in the 30 to 49 year-old age group with either cytology or visual inspection with acetic acid (VIA), regardless of HIV status. While practical, these guidelines may not adequately account for the high prevalence of HIV in Botswana and the higher risk of early cervical cancer progression. There is limited published data from Botswana on the prevalence of pre-invasive disease and the role of screening in younger women.

This study describes the association of age and HIV status with VIA positivity and high-grade cervical pre-cancer disease. We aimed to determine how initiating cervical cancer screening at age 25 years, instead of 30 years, in WLWH would improve the identification of highgrade pre-invasive cervical disease without unduly increasing overtreatment of low-grade cervical dysplasia. Data presented here could strengthen the evidence for the WHO recommendation on the target age group for cervical cancer screening in WLWH. 


\section{Methods}

\section{Study design and patient selection}

We conducted a retrospective cross-sectional study based on the Botswana Ministry of Health and Wellness (MOHW) National Cervical Cancer Prevention Programme "see-and-treat" pilot programmatic database.[17] The database included women screened with visual inspection after acetic acid (VIA) at Bontleng clinic and those referred to Princess Marina Hospital (PMH) for colposcopy in Gaborone, Botswana, from March 2009 through August 2015. Cervical cancer screening services were initially provided for WLWH as part of comprehensive HIV care and were later extended to HIV-negative women at these sites. Screening services were offered free of charge to all Botswana citizens.

Screening services were linked to a physician-led referral colposcopy and loop electrosurgical excision procedure (LEEP) clinic at PMH. Through various channels, women came to screening services, including provider referral, self-referral following sensitization by written materials, and health education talks. Women were excluded from screening if they had previously had a hysterectomy, pelvic radiation for lower genital tract cancer, or a cervical cancer diagnosis. Screening for women who were menstruating heavily, pregnant, or had a persistent vaginal discharge was re-scheduled for after resolution of the condition.

\section{Cervical cancer screening procedures}

All patients underwent a speculum examination of the cervix by a nurse who had participated in the Botswana MOHW VIA training program. Visual assessment was performed after applying $5 \%$ acetic acid to the cervix using a cotton swab, and findings were categorized as normal, abnormal with a recommendation for cryotherapy, or abnormal with a recommendation for LEEP. Those with abnormal lesions eligible for cryotherapy were offered same-day treatment and had no histopathology specimen collected. Women with abnormal lesions ineligible for cryotherapy based on appearance, size, or extension into the cervical os, were referred to the colposcopy/LEEP clinic and evaluated by a specialist gynecologist or trained medical officers. The colposcopic appearance of lesions determined diagnostic and treatment decisions. Low-grade appearing lesions were treated with cautery after taking a biopsy; high-grade appearing lesions or those extending into the cervical were treated by LEEP. Histopathology specimens were read by pathologists blinded to VIA findings.

\section{HIV procedures}

Women with unknown HIV status at the time of screening or with documented HIV negative status more than six months prior were referred to an HIV testing center and requested to share their results. Throughout the study period, the Botswana National HIV program initiated anti-retroviral treatment (ART) at a CD4 count of $\leq 350$ cells $/ \mu \mathrm{L}$.

\section{Data collection}

All women undergoing VIA screening completed a questionnaire capturing a limited set of patient-level cervical cancer risk factors, including smoking, age of sexual debut, and parity. HIV status was recorded, and for WLWH, CD4 count at the time of HIV diagnosis and whether on ART at the time of screening was documented. VIA screening outcomes were recorded in the programmatic database. Histology results of women referred for colposcopy/LEEP were extracted from the National Health Laboratory (NHL) electronic medical record when available and entered into the programmatic database.

\section{Outcomes}

The primary outcome was the association of VIA positivity and age adjusting for cervical cancer risk factors. The secondary outcomes were the association of histopathologically confirmed high-grade pre-cancer and age adjusting for cervical cancer risk factors; HIV-status association with VIA positivity and high-grade pre-cancer; and the proportions of VIA positivity and high-grade pre-cancer by both age and HIV status.

\section{Data analysis}

The analyzed dataset included only women between the ages of 25 and 49. Patient records with missing data for VIA or histopathology that could not be corrected by cross-reference with primary records were excluded from the primary and secondary analysis, respectively. The sample size for the primary outcome was calculated using a 1-sided alpha of 0.05 . To attain a $99 \%$ power, we assumed VIA positivity to be $30 \%$ in women aged 25 to 29 years and $20 \%$ in women aged 30 to 49 years based on previous findings.[17] The sample size required to detect a statistically significant difference in VIA-positivity between the two age groups was 2,076 women (374 women aged 25 to 29 years and 1,702 women aged 30 to 49 years). 
The cervical cancer risk factors adjusted for included: HIV status, parity, smoking, and age of sexual debut. CD4 count and ART were included in the analysis of WLWH. Descriptive statistics for these variables are presented as median [interquartile range (IQR)] and proportions. Continuous variables were categorized into binary variables and compared using the chi-square test. Categorical variables included age groups of younger and older women ( 25 to 29 years; 30 to 49 years), age of sexual debut ( $\leq 18$; $>18$ years), parity ( $\leq 2 ;>2$ ), CD 4 count ( $\leq 350$ cells $/ \mu \mathrm{L} ;>350$ cells $/ \mu \mathrm{L}$ ), and histopathology results (benign or CIN 1 [ $\leq$ CIN1] for low-grade pre-cancer; CIN2+ for highgrade pre-cancer). Patterns of missing data were described for the study cohort using percentages.

Logistic regression models computed unadjusted and adjusted odds ratios (ORs) with 95\% confidence intervals (CI). Only exposure variables with a p-value of less than 0.1 for unadjusted ORs were included in the adjusted regression models.[18] A p-value of less than 0.05 was considered to be statistically significant. We used Stata 14.0 (StataCorp LLC, College Station, Texas).

\section{Results}

\section{Overall patient characteristics}

The database included 5,724 women aged 25 through 49 years screened with VIA between March 2009 and August 2015 (Fig. 1). Ten women had missing VIA data, leaving 5,714 women for the VIA analysis. As shown in Table 1, the median age was 35 years [IQR 31-39], and 1029 (18\%) were between 25 and 29 years of age. Smoking was reported by 285 (5\%) of the women. The median age of sexual debut was 18 years [IQR 17-20], and the median parity was two [IQR 1-3]. HIV status was known in 5,583 (98\%), and 5,026 (90\%) of those with a known status were WLWH. Eight hundred and forty nine (86\%) of the women aged 25 to 29 years and 4,177 (91\%) of the those aged 30 to 49 years were WLWH. Among the WLWH, the median CD4 count was 250 cells/ $\mu \mathrm{L}$ [IQR 150-428], and 1628 (34.2\%) were on ART. Missing data was $\leq 5 \%$ for all the variables except for CD4 count $(11 \%, n=551)$. The level of CD4 count missing data was similar for both age groups (10.5\% for 25 to 29 year-olds versus $11.1 \%$ for 30 to 49 year-olds). 
Demographic and clinical characteristics of all study participants

\begin{tabular}{|c|c|c|c|c|c|}
\hline \multirow[t]{2}{*}{ Variable } & \multicolumn{2}{|l|}{ All } & \multirow{2}{*}{$\begin{array}{l}\text { Age } 25-29 \text { years } \\
n^{a}(\%)\end{array}$} & \multirow{2}{*}{$\begin{array}{l}\text { Age } 30-49 \text { years } \\
n^{a}(\%)\end{array}$} & \multirow{2}{*}{$\begin{array}{l}\text { P-Value } \\
\text { for } X^{2} \text { test }\end{array}$} \\
\hline & $n(\%)$ & Median [IQR] & & & \\
\hline Age & 5,714 & $35[31,39]$ & & & \\
\hline Smoking & 5,661 & & $1,018(18.0)$ & $4,643(82.0)$ & $0.008^{b}$ \\
\hline Yes & $285(50.0)$ & & $68(6.7)$ & $217(4.7)$ & \\
\hline No & $5,376(94.1)$ & & 950 (93.3) & 4,426 (95.3) & \\
\hline Missing & $53(1.0)$ & & & & \\
\hline Sexual debut & 5,689 & $18[17,21]$ & $1,024(18.0)$ & $4,665(82.0)$ & $0.02^{b}$ \\
\hline$\leq 18$ & $3,150(55.3)$ & & $533(52.1)$ & $2,617(56.1)$ & \\
\hline$>18$ & $2,539(44.4)$ & & 491 (47.9) & $2,048(43.9)$ & \\
\hline Missing & $25(0.4)$ & & & & \\
\hline Parity & 5,612 & $2[1,3]$ & $1,001(17.8)$ & $4,611(82.2)$ & $<0.001^{b}$ \\
\hline$\leq 2$ & $3,223(56.4)$ & & 815 (81.4) & $2,408(52.2)$ & \\
\hline$>2$ & $2,389(41.8)$ & & $186(18.6)$ & $2,203(47.8)$ & \\
\hline Missing & $102(1.8)$ & & & & \\
\hline HIV Status & 5,583 & & 989 (17.7) & $4,594(82.3)$ & $<0.001^{b}$ \\
\hline Negative & 557 (9.7) & & $140(14.2)$ & 417 (9.1) & \\
\hline Positive & $5,026(88.0)$ & & $849(85.8)$ & 4,177 (90.9) & \\
\hline Missing & 131 (2.3) & & & & \\
\hline Initial CD4 at HIV Diagnosis ${ }^{c}$ & 4,475 & $250[150,428]$ & $760(16.9)$ & $3,715(83.1)$ & $<0.001^{\mathrm{b}}$ \\
\hline$\leq 350$ & $2,308(45.9)$ & & $304(40.0)$ & $2,004(53.9)$ & \\
\hline$>350$ & $2,167(43.1)$ & & $456(60.0)$ & $1,711(46.1)$ & \\
\hline Missing & $551(11.0)$ & & & & \\
\hline On ART at time of screening ${ }^{c}$ & 4,766 & & $802(16.8)$ & $3,964(83.2)$ & $<0.001^{\mathrm{b}}$ \\
\hline Yes & $1,628(32.4)$ & & $346(43.1)$ & $1,282(32.3)$ & \\
\hline No & $3,138(62.4)$ & & $456(56.9)$ & $2,682(67.7)$ & \\
\hline Missing & $260(5.2)$ & & & & \\
\hline VIA Results & 5,714 & & $1,029(18.0)$ & $4,685(82.0)$ & $<0.001^{\mathrm{b}}$ \\
\hline Positive & $1,959(34.3)$ & & $428(41.6)$ & $1,531(32.7)$ & \\
\hline Negative & $3,755(65.7)$ & & $601(58.4)$ & $3,154(67.3)$ & \\
\hline \multicolumn{6}{|c|}{$\begin{array}{l}\text { Abbreviation: ART, anti-retroviral treatment; CIN, cervical intraepithelial neoplasia; IQR, inter-quartile range; VIA, visual inspection after } \\
\text { acetic acid. }\end{array}$} \\
\hline \multicolumn{6}{|c|}{ The number of women in levels of categorical variable may not add up to total " $n$ " because missing category has been removed. } \\
\hline \multicolumn{6}{|l|}{${ }^{b}$ for $p<0.05$. } \\
\hline${ }^{\mathrm{c}}$ for HIV positive patients only & & & & & \\
\hline
\end{tabular}

\section{Via-positivity}


The overall VIA positivity of the study population was $34.3 \%(n=1,959)$. The proportion was higher in the 25 to 29 year-olds $(41.5 \%$, $n=$ $428)$ than the 30 to 49 year-olds $(32.7 \%, n=1,531)$. The WLWH had a higher VIA positivity rate $(35.9 \%, n=1,841)$ than HIV-negative women $(24.1 \%, n=141)$ (Table 2). 
Table 2

Study participants' characteristics with bivariate and multivariable odds ratio for VIA positivity

\begin{tabular}{|c|c|c|c|c|c|c|c|}
\hline Variable & $\begin{array}{l}\text { All } \\
\text { n (\%) }\end{array}$ & $\begin{array}{l}\text { VIA } \\
\text { Positive } \\
\mathrm{n}^{\mathrm{a}}(\%)\end{array}$ & $\begin{array}{l}\text { VIA } \\
\text { Negative } \\
\mathrm{n}^{\mathrm{a}}(\%)\end{array}$ & $\begin{array}{l}\text { VIA Positivity } \\
\text { BVA Odds } \\
\text { Ratios } \\
(95 \% \mathrm{Cl})\end{array}$ & P-value & $\begin{array}{l}\text { VIA Positivity } \\
\text { MVA Odds } \\
\text { Ratios } \\
(95 \% \mathrm{Cl})\end{array}$ & $\begin{array}{l}\text { P-value } \\
\text { for } X^{2} \\
\text { test }\end{array}$ \\
\hline $\begin{array}{l}\text { Age Group } \\
25-29 \text { years } \\
30-49 \text { years }\end{array}$ & $\begin{array}{l}\mathbf{5 , 7 1 4} \\
1,029(18.0) \\
4,685(82.0)\end{array}$ & $\begin{array}{l}1,959 \\
(34.3) \\
428(41.6) \\
1,531 \\
(32.7)\end{array}$ & $\begin{array}{l}3,755 \\
(65.7) \\
601(58.4) \\
3,154 \\
(67.3)\end{array}$ & $\begin{array}{l}1.47(1.28, \\
1.69) \\
\text { Ref }\end{array}$ & $e^{<} .001^{b}$ & $\begin{array}{l}1.48(1.28 \\
1.72)\end{array}$ & $<0.001^{b}$ \\
\hline $\begin{array}{l}\text { Smoker } \\
\text { No } \\
\text { Yes } \\
\text { Missing }\end{array}$ & $\begin{array}{l}5,661 \\
5,376(94.1) \\
285(5.0) \\
53(0.9)\end{array}$ & $\begin{array}{l}\text { 1,937 } \\
(34.2) \\
1,825 \\
(33.9) \\
112(39.3)\end{array}$ & $\begin{array}{l}3,724 \\
(65.8) \\
3,551 \\
(66.1) \\
173(60.7)\end{array}$ & $\begin{array}{l}\text { Ref } \\
1.27(1.00,1.62)\end{array}$ & 0.053 & $\begin{array}{l}1.14(0.89 \\
1.46)\end{array}$ & 0.31 \\
\hline $\begin{array}{l}\text { Age Sexual debut } \\
\leq 18 \\
>18 \\
\text { missing }\end{array}$ & $\begin{array}{l}5,689 \\
3,150(55.1) \\
2,539(44.4) \\
25(0.5)\end{array}$ & $\begin{array}{l}1,950 \\
(34.3) \\
1,075 \\
(34.1) \\
875(34.5)\end{array}$ & $\begin{array}{l}3,739 \\
(65.7) \\
\\
2,075 \\
(65.9) \\
1,664 \\
(65.5)\end{array}$ & $\begin{array}{l}0.99(0.88,1.10) \\
\text { Ref }\end{array}$ & 0.79 & $\mathrm{~N} / \mathrm{A}$ & $\mathrm{N} / \mathrm{A}$ \\
\hline $\begin{array}{l}\text { Parity } \\
\leq 2 \\
>2 \\
\text { Missing }\end{array}$ & $\begin{array}{l}\mathbf{5 , 6 1 2} \\
3,223 \\
(56.40) \\
2,389 \\
(41.81) \\
102(1.79)\end{array}$ & $\begin{array}{l}1,151 \\
(35.7) \\
773(32.4)\end{array}$ & $\begin{array}{l}3,688 \\
(65.7) \\
\\
2,072 \\
(64.3) \\
\\
1,616 \\
(67.6)\end{array}$ & $\begin{array}{l}\text { Ref } \\
0.86(0.77 \\
0.96)\end{array}$ & $0.009^{b}$ & $\begin{array}{l}0.88(0.79 \\
0.99)\end{array}$ & $0.04^{b}$ \\
\hline $\begin{array}{l}\text { HIV Status } \\
\text { Negative } \\
\text { Positive } \\
\text { Missing }\end{array}$ & $\begin{array}{l}5,583 \\
557(9.74) \\
5,026 \\
(87.96) \\
131(2.30)\end{array}$ & $\begin{array}{l}1,941 \\
(34.8) \\
134(24.1) \\
1,807 \\
(35.9)\end{array}$ & $\begin{array}{l}3,642 \\
(65.2) \\
423(75.9) \\
3,219 \\
(64.1)\end{array}$ & $\begin{array}{l}\text { Ref } \\
1.77(1.45, \\
2.17)\end{array}$ & $\begin{array}{l}< \\
0.001^{b}\end{array}$ & $\begin{array}{l}1.85(1.51 \\
2.28)\end{array}$ & $<0.001^{b}$ \\
\hline
\end{tabular}

Abbreviations: ART, anti-retroviral therapy; BVA, bivariate analysis; MVA, multivariate analysis; VIA, visual inspection after acetic acid.

a The number of women in levels of categorical variable may not add up to total " $n$ " because missing category has been removed.

b for $p<0.05$

${ }^{\mathrm{c}}$ for HIV positive patients only. 


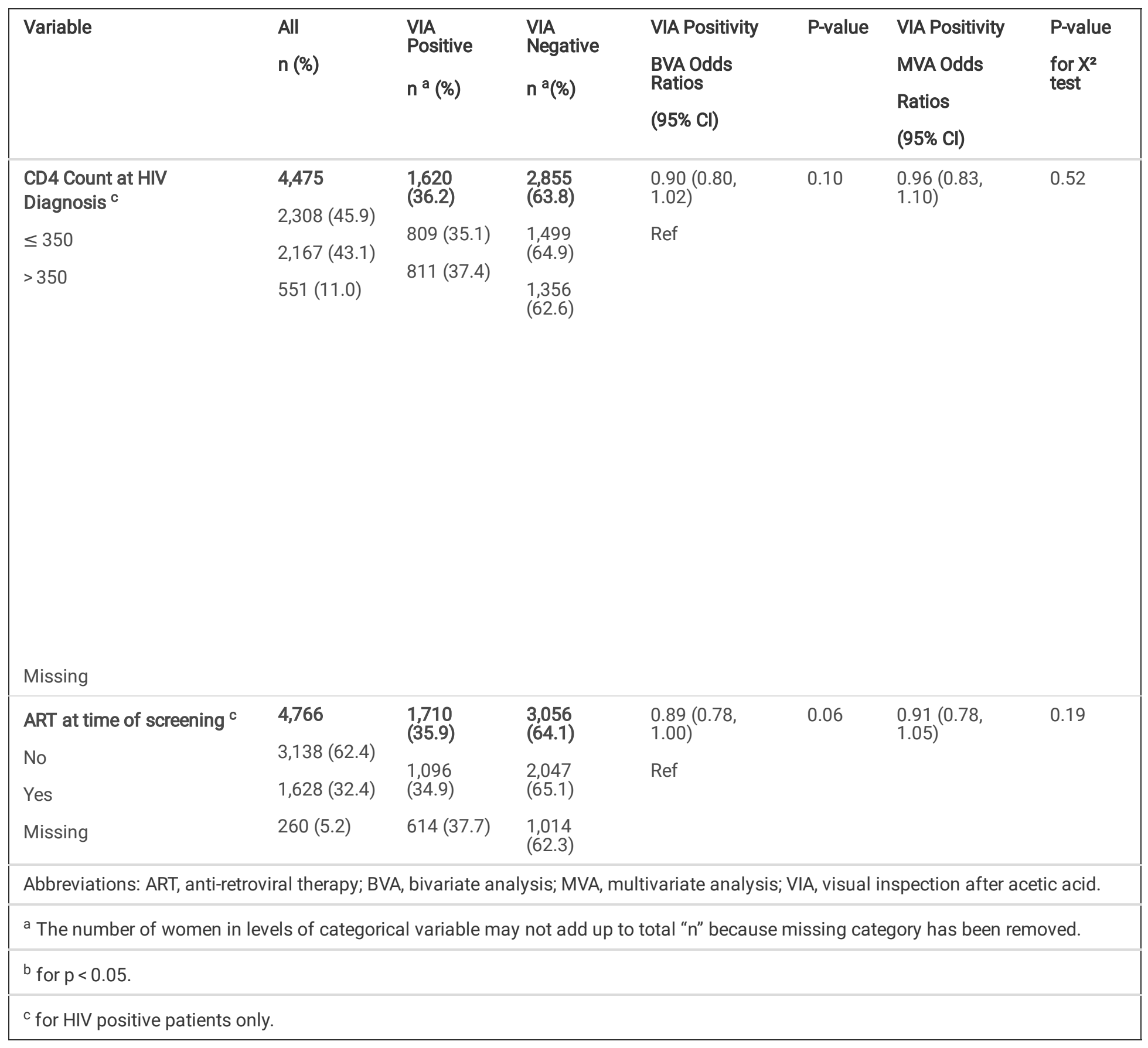

In multivariate analyses, VIA positivity was more likely in 25 to 29 year-olds than in 30 to 49 year-olds $(\mathrm{OR} 1.48, \mathrm{Cl} 1.28,1.72)$, and in WLWH compared to HIV-negative women (OR 1.85, $\mathrm{Cl} 1.51,2.28)$. Among WLWH, VIA positivity was not affected by CD4 count $(\mathrm{OR}=0.96$, $\mathrm{Cl} 0.83,1.10)$ or by ART $(\mathrm{OR}=0.91, \mathrm{Cl} 0.78,1.05)$ (Table 2$)$.

\section{High-grade Pre-cancer}

The majority of the VIA-positive lesions were ineligible for treatment with cryotherapy $(68 \%, n=1,330)$; this was similar for both the 25 to 29 year-olds and the 30 to 49 year-olds ( $67.1 \%$ versus $68.1 \%$, respectively). Of the 1,330 women referred to colposcopy/LEEP, 878 (66\%) attended and had recorded histopathology results ( $58.5 \%$ for 25 to 29 year-olds, and $68.1 \%$ for $30-49$ year-olds). The overall population CIN2 + point prevalence was $10.1 \%$ (10.9\% for 25 to 29 year-olds and $9.9 \%$ for 30 to 49 year-olds) (Fig. 1 \&Table 3). 
Table 3

VIA and histological outcomes by age group and HIV status

\begin{tabular}{|c|c|c|c|c|c|c|}
\hline \multicolumn{7}{|l|}{ VIA outcomes } \\
\hline & \multicolumn{2}{|c|}{ All participants } & \multicolumn{2}{|c|}{ HIV positive ${ }^{a}$} & \multicolumn{2}{|c|}{ HIV negative ${ }^{b}$} \\
\hline & $25-29$ & $30-49$ & $25-29$ & $30-49$ & $25-29$ & $30-49$ \\
\hline & Age group & Age group & Age group & Age group & Age group & age group \\
\hline Number Screened with VIA & $N=1029$ & $N=4685$ & $n=849$ & $N=4177$ & $N=140$ & $N=417$ \\
\hline VIA Results & $601(58.4 \%)$ & $3154(67.3 \%)$ & $472(55.6 \%)$ & $2747(65.8 \%)$ & $95(67.9 \%)$ & $328(78.7 \%)$ \\
\hline Negative & $428(41.6 \%)$ & $1531(32.7 \%)$ & $377(44.4 \%)$ & $1430(34.2 \%)$ & $45(32.1 \%)$ & $89(21.3 \%)$ \\
\hline \multicolumn{7}{|l|}{ Positive } \\
\hline Eligible for cryotherapy & $141(32.9 \%)$ & $488(31.9 \%)$ & $121(32 \%)$ & $477(33.4 \%)$ & $18(40 \%)$ & $34(38.2 \%)$ \\
\hline Not eligible for cryotherapy & $287(67.1 \%)$ & $1043(68.1 \%)$ & $256(68 \%)$ & $953(66.6 \%)$ & $27(60 \%)$ & $55(61.8 \%$ \\
\hline \multicolumn{7}{|l|}{ Histology outcomes } \\
\hline $\begin{array}{l}\text { Not eligible for cryotherapy, arrived at } \\
\text { Colposcopy with histology results }\end{array}$ & $N=168$ & $N=710$ & $n=149$ & $n=659$ & $N=16$ & $N=46$ \\
\hline$\leq \mathrm{CIN} 1$ & $56(33.3 \%)$ & $247(34.8 \%)$ & $46((30.9 \%)$ & $209(31.7 \%)$ & $8(50 \%)$ & $36(78.2 \%)$ \\
\hline$\geq \mathrm{CIN} 2+$ & $112(66.7 \%)$ & $463(65.2 \%)$ & $103(69.1 \%)$ & $450(68.3 \%)$ & $8(50 \%)$ & $10(21.8 \%)$ \\
\hline \multirow[t]{2}{*}{$\geq \mathrm{CIN} 2+$ in screened population } & $112 / 1029$ & $463 / 4685$ & $103 / 849$ & $450 / 4177$ & $8 / 140$ & $10 / 417$ \\
\hline & $(10.9 \%)$ & $(9.9 \%)$ & $(12.1 \%)$ & $(10.8 \%)$ & $(5.7 \%)$ & $(2.4 \%)$ \\
\hline
\end{tabular}

In multivariate analyses, CIN2 + was associated with a positive HIV status (aOR 6.12, $\mathrm{Cl} 3.39,11.10)$, but not with age (OR 1.07, $\mathrm{Cl} 0.75$ 1.52 for 25 to 29 year-olds compared to 30 to 49 year-olds). In WLWH, neither CD4 count nor ART was associated with CIN2+ (Table 4). 
Table 4

All Study participants' characteristics with bivariate and multivariable odds ratio for CIN2+

\begin{tabular}{|c|c|c|c|c|c|c|c|}
\hline Variable & $\begin{array}{l}\text { All } \\
\text { n (\%) }\end{array}$ & $\begin{array}{l}\geq \mathrm{CIN} 2+ \\
\mathrm{n}^{\mathrm{a}}(\%)\end{array}$ & $\begin{array}{l}\leq \mathrm{CIN} 1 \\
\mathrm{n}^{\mathrm{a}}(\%)\end{array}$ & $\begin{array}{l}\text { CIN2+ } \\
\text { BVA Odds } \\
\text { Ratios } \\
(95 \% \mathrm{Cl})\end{array}$ & P-value & $\begin{array}{l}\text { CIN2+ } \\
\text { MVA Odds } \\
\text { Ratios } \\
(95 \% \mathrm{Cl})\end{array}$ & $\begin{array}{l}\text { P-value } \\
\text { for } X^{2} \\
\text { test }\end{array}$ \\
\hline $\begin{array}{l}\text { Age Group } \\
25-29 \text { years } \\
30-49 \text { years }\end{array}$ & $\begin{array}{l}878 \\
168 \\
(19.1) \\
710 \\
(80.9)\end{array}$ & $\begin{array}{l}575(65.5) \\
112(66.7) \\
463(65.2)\end{array}$ & $\begin{array}{l}303 \\
(34.5) \\
56(33.3) \\
247 \\
(34.8)\end{array}$ & $\begin{array}{l}1.07(0.75,1.52) \\
\text { Ref }\end{array}$ & 0.72 & N/A & N/A \\
\hline $\begin{array}{l}\text { Yes } \\
\text { Missing }\end{array}$ & $\begin{array}{l}867 \\
817 \\
(93.1) \\
50(5.7) \\
11(1.2)\end{array}$ & $36(72.0)$ & $\begin{array}{l}301 \\
(34.7) \\
287 \\
(35.1) \\
14(28.0)\end{array}$ & $\begin{array}{l}\text { Ref } \\
1.38(0.74,2.62)\end{array}$ & 0.30 & N/A & N/A \\
\hline $\begin{array}{l}\text { Age Sexual debut } \\
\leq 18 \\
>18 \\
\text { missing }\end{array}$ & $\begin{array}{l}873 \\
505 \\
(57.5) \\
368 \\
(41.9) \\
5(0.6)\end{array}$ & $\begin{array}{l}572(65.5) \\
338(66.9) \\
234(63.6)\end{array}$ & $\begin{array}{l}301 \\
(34.5) \\
167 \\
(33.1) \\
134 \\
(36.4)\end{array}$ & $\begin{array}{l}1.16(0.87,1.54) \\
\text { Ref }\end{array}$ & 0.31 & N/A & N/A \\
\hline $\begin{array}{l}\text { Parity } \\
\leq 2 \\
>2 \\
\text { Missing }\end{array}$ & $\begin{array}{l}861 \\
517 \\
(58.9) \\
344 \\
(39.2) \\
17(2.0)\end{array}$ & $\begin{array}{l}566(65.7) \\
328(63.4) \\
238(69.2 \%)\end{array}$ & $\begin{array}{l}295 \\
(34.3) \\
189 \\
(36.6) \\
106 \\
(30.8)\end{array}$ & $\begin{array}{l}\text { Ref } \\
1.29(0.97,1.73)\end{array}$ & 0.08 & $1.30(0.96,1.75)$ & 0.09 \\
\hline
\end{tabular}

Abbreviations: ART, anti-retroviral therapy; BVA, bivariate analysis; MVA, multivariate analysis; VIA, visual inspection after acetic acid.

a The number of women in levels of categorical variable may not add up to total " $n$ " because missing category has been removed.

${ }^{b}$ for $p<0.05$.

${ }^{c}$ for HIV positive patients only. 


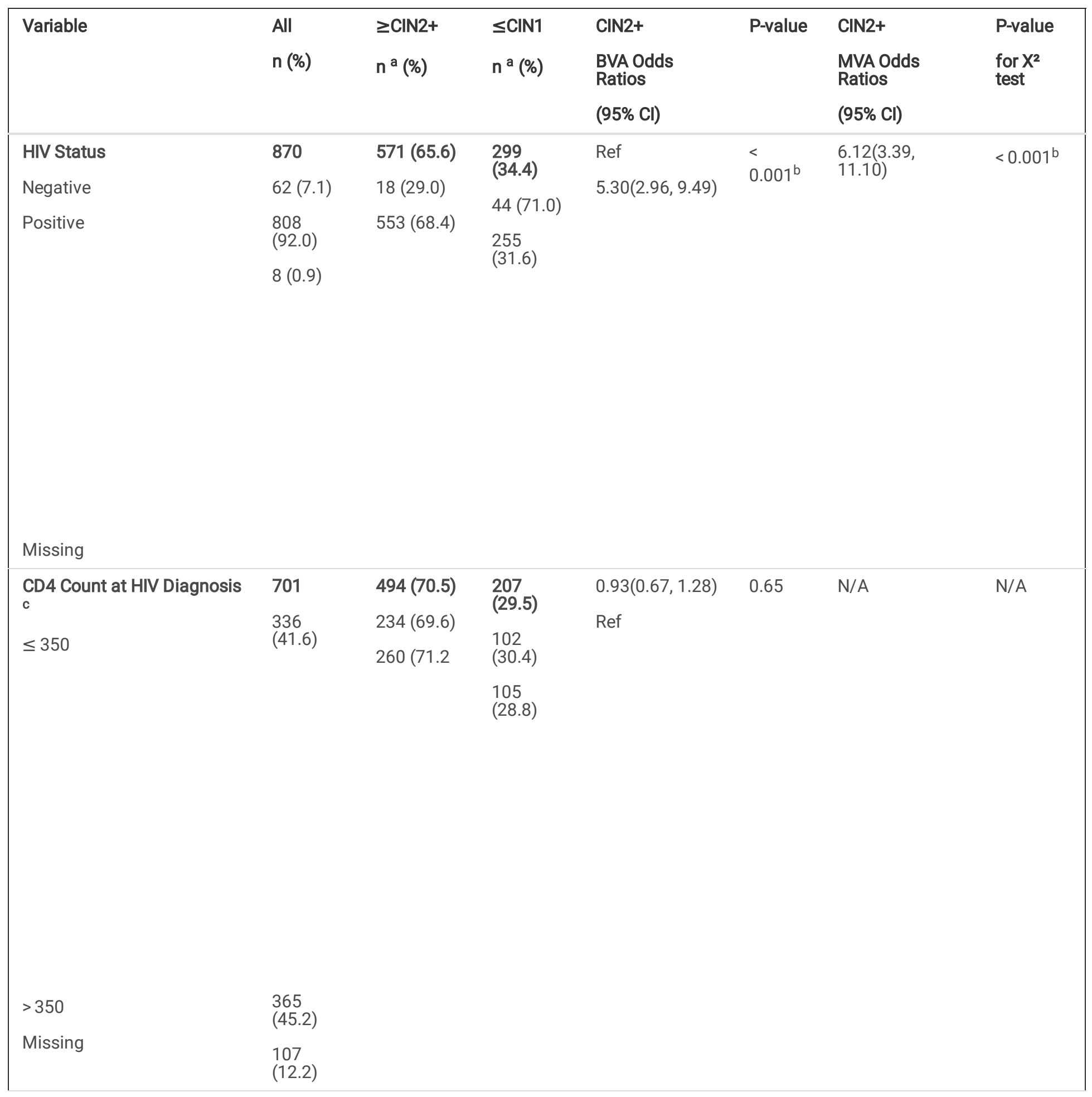

Abbreviations: ART, anti-retroviral therapy; BVA, bivariate analysis; MVA, multivariate analysis; VIA, visual inspection after acetic acid.

a The number of women in levels of categorical variable may not add up to total " $n$ " because missing category has been removed.

${ }^{b}$ for $p<0.05$.

${ }^{\mathrm{c}}$ for HIV positive patients only. 


\begin{tabular}{|c|c|c|c|c|c|c|c|}
\hline Variable & $\begin{array}{l}\text { All } \\
n(\%)\end{array}$ & $\begin{array}{l}\geq \mathrm{CIN} 2+ \\
\mathrm{n}^{\mathrm{a}}(\%)\end{array}$ & $\begin{array}{l}\leq \mathrm{CIN} 1 \\
\mathrm{n}^{\mathrm{a}}(\%)\end{array}$ & $\begin{array}{l}\text { CIN2+ } \\
\text { BVA Odds } \\
\text { Ratios } \\
(95 \% \mathrm{Cl})\end{array}$ & P-value & $\begin{array}{l}\text { CIN2+ } \\
\text { MVA Odds } \\
\text { Ratios } \\
(95 \% \mathrm{Cl})\end{array}$ & $\begin{array}{l}\text { P-value } \\
\text { for } X^{2} \\
\text { test }\end{array}$ \\
\hline $\begin{array}{l}\text { ART at time of screening }{ }^{c} \\
\text { No } \\
\text { Yes } \\
\text { Missing }\end{array}$ & $\begin{array}{l}455 \\
(56.3) \\
318 \\
(39.4) \\
35(4.3)\end{array}$ & $\begin{array}{l}527(68.2) \\
315(69.2) \\
212(66.7)\end{array}$ & $\begin{array}{l}246 \\
(31.8) \\
140 \\
(30.8) \\
106 \\
(33.3)\end{array}$ & Ref & 0.45 & N/A & N/A \\
\hline \multicolumn{8}{|c|}{ Abbreviations: ART, anti-retroviral therapy; BVA, bivariate analysis; MVA, multivariate analysis; VIA, visual inspection after acetic acid. } \\
\hline \multicolumn{8}{|c|}{ a The number of women in levels of categorical variable may not add up to total " $\mathrm{n}$ " because missing category has been removed. } \\
\hline \multicolumn{8}{|c|}{${ }^{b}$ for $p<0.05$} \\
\hline
\end{tabular}

\section{Via-positivity And High-grade Pre-cancer By Age And Hiv-status}

In WLWH, the 25 to 29 year-olds were more likely to be VIA positive than the 30 to 49 year-olds $(44.41 \%, n=377$ versus $34.2 \%, n=1430$, respectively). We observed a similar pattern for HIV-negative women ( $32.1 \%, \mathrm{n}=45$ for 25 to 29 year-olds, compared to $21.3 \%, \mathrm{n}=89$ for 49 year-olds). The overall proportion of CIN2 + in WLWH was $11 \%$ (12.1\% for the 25 to 29 year-olds and $10.8 \%$ for the 30 to 49 year-olds). The overall proportion of CIN2 + in HIV-negative women was 3.2\% (5.7\% for 25 to 29 year-olds and $2.4 \%$ for 30 to 49 year-olds) (Table 3).

\section{Discussion}

WLWH aged 25 through 29 years attending routine cervical cancer screening in our national program had the same odds of having highgrade cervical pre-cancer as women aged 30 to 49 years. Prior research has indicated a link between younger age and cervical cancer among WLWH. $[5,8,9]$ Our findings confirm the presence of a significant level of cervical cancer precursors requiring intervention in women as young as 25 years, particularly in WLWH, thus supporting the new WHO recommendation to lower the age of initiation of cervical cancer screening from 30 to 25 years in WLWH.

A concern about lowering the cervical cancer screening age is that clinically insignificant lesions from transient HPV infections would be intervened upon unnecessarily, resulting in overtreatment of young women.[19,20] Although women in this cohort aged 25 through 29 years had higher rates of VIA positivity than women aged 30 to 49 years, similar proportions were referred for the excisional procedure. The histopathology results indicate that the proportions of CIN2 + detected and appropriately treated were similar for the two age groups in WLWH. The proportion of CIN2 + was more than three times lower in HIV-negative women than in WLWH, and younger women were twice more likely to have CIN2+. If overtreatment did occur, it would primarily have occurred in the group of women treated with cryotherapy, a treatment that ultimately has minimal side effects.[21]

We had expected to find a correlation between patient age and high-grade dysplasia because older women would have had a longer time to progress from HPV infection to cervical pre-cancer without opportunities for intervention.[22] However, our data do not support this hypothesis. Instead, younger women overall and in WLWH had a similar proportion of CIN2 + to older women. Data is limited on HPV progression to cervical pre-cancer and cancer in women aged 20 to 29 years. Adolescent WLWH are more likely to have HPV co-infections and coexisting abnormalities, albeit low-grade, relative to their HIV-negative counterparts.[23] The shorter timeline from HPV infection to the development of pre-cancer in adolescent WLWH is in line with our finding of high rates of high-grade pre-cancer in the 25 to 29 yearolds because of the likey accelerated timeframe of progression of pre-cancer from low- to high-grade.

Our analysis has limitations because it utilized a programmatic database that collected limited patient-level demographic and risk factor data. CD 4 count had $11 \%$ missing data; however, this was similar for both age groups, and we doubt that it would have had a significant effect on the outcomes. The rate of cryotherapy ineligibility was high, but high rates have been observed in other high HIV burden areas. [24] This high rate could be related to lack of prior screening and high rates of cervicitis.[25] Documentation of colposcopy/LEEP referral 
appointment attendance was not recorded, and thus histopathology results may not represent the entire cohort of women who had a colposcopic evaluation. However, the population point prevalence of the screened cohort was similar for the two age groups when computed using the available histology results proportions. Key HIV-related variables, including viral load and timing of HIV treatment, were not collected, and therefore, the full extent of the immune status of WLWH could not be assessed. Finally, the determination of the proportion of women with high-grade dysplasia was further limited by the lack of histopathology data in women who underwent cryotherapy and the sensitivity of VIA. The accuracy of VIA positivity is affected by the prevalence of cervicitis related to sexually transmitted infections, and high rates of cervicitis have been reported in WLWH in Botswana.[25]

\section{Conclusions}

Despite the limitations of this study, we present new evidence of the significant burden of CIN2 + in younger WLWH in Botswana. Until the population-level effects of HPV vaccination and universal ART to improve overall immune competence in WLWH are realized,[26] the reduction in cervical cancer in LMICs will depend on effective, comprehensive screening programs for WLWH. This additional evidence further supports the current WHO conditional recommendation for initiating screening at age 25.

\section{Abbreviations}

ART: Anti-retroviral treatment; Cl: Confidence interval; CIN: Cervical intraepithelial neoplasia; HIC: High-income country; HIV: Human immunodeficiency virus; HPV: Human papillomavirus; HRDC: Health research and development committee; LEEP: Loop electro-surgical excision procedure; LMIC: Low-middle income county; IQR: Interquartile range; MOHW: Ministry of health and wellness; NHL: National health laboratory OR: Odds ratio; PMH: Princess Marina hospital; VIA: Visual inspection after acetic acid; WHO: World Health Organization; WLHV: Women living with HIV

\section{Declarations}

\section{Ethics approval and consent to participate}

The Health Research and Development Committee (HRDC) of the Botswana Ministry of Health and Wellness (MOHW) approved this analysis (HPDME-13/181). Patient consent was waived as this was a secondary analysis of routinely collected programmatic data. All methods were performed in accordance with the Declaration of Helsinki.

\section{Consent for publication}

Not applicable

\section{Availability of data and materials}

The datasets generated during the current study are available from the corresponding author on reasonable request.

\section{Competing interests}

No competing interests declared by the authors

\section{Funding}

The development of the 'see and treat' pilot program database was undertaken as part of the PEPFAR-supported Botswana-UPenn Partnership Technical assistance for in-service training for health care providers in Botswana (U2GPS001949)

\section{Author contributions}

Study conception and design: DRM, RL, SG; Acquisition of data: BM, DRM; Analysis and interpretation of data: DRM, RL, SG, GJH, AM, CM, LG ; Drafting of manuscript: DRM, RL, SG; Critical revision: GJH, CM, LBM, AM. All authors approved the manuscript before submission.

\section{Acknowledgments}

We acknowledge with thanks the contributions of Harvey Friedman, Nicola Zetola, Ari Ho-Foster, Balladia Kizoto, and Kadimo Khutsafalo.

\section{References}


1. Arbyn M, Weiderpass E, Bruni L, et al. Estimates of incidence and mortality of cervical cancer in 2018: a worldwide analysis. Lancet Glob Health. 2020;8(2):e191-e203.

2. Sung H, Ferlay J, Siegel RL, et al. Global cancer statistics 2020: GLOBOCAN estimates of incidence and mortality worldwide for 36 cancers in 185 countries. CA Cancer J Clin. 2021.

3. Dryden-Peterson S, Bvochora-Nsingo M, Suneja G, et al. HIV Infection and Survival Among Women With Cervical Cancer. J Clin Oncol. 2016;34(31):3749-57.

4. Peirson L, Fitzpatrick-Lewis D, Ciliska D, et al. Screening for cervical cancer: a systematic review and meta-analysis. Syst Rev. 2013;2:35.

5. Grabar S, Hleyhel M, Belot A, et al. Invasive cervical cancer in HIV-infected women: risk and survival relative to those of the general population in France. Results from the French Hospital Database on HIV (FHDH)-Agence Nationale de Recherches sur le SIDA et les Hepatites Virales (ANRS) CO4 cohort study. HIV Med. 2019;20(3):222-9.

6. Stelzle D, Tanaka LF, Lee KK, et al. Estimates of the global burden of cervical cancer associated with HIV. Lancet Glob Health. 2021;9(2):e161-e9.

7. Liu G, Sharma M, Tan N, et al. HIV-positive women have higher risk of human papilloma virus infection, precancerous lesions, and cervical cancer. AIDS. 2018;32(6):795-808.

8. Grover S, Bvochora-Nsingo M, Yeager A, et al. Impact of Human Immunodeficiency Virus Infection on Survival and Acute Toxicities From Chemoradiation Therapy for Cervical Cancer Patients in a Limited-Resource Setting. Int J Radiat Oncol Biol Phys. 2018;101(1):201-10.

9. Mpunga T, Znaor A, Uwizeye FR, et al. A case-control study of HIV infection and cancer in the era of antiretroviral therapy in Rwanda. International journal of cancer Journal international du cancer. 2018;143(6):1348-55.

10. Cancer screening in the European Union. Cancer screening in the European Union. Report on the implementation of the council recommendation on cancer. Screening 2017 [Available from:

https://ec.europa.eu/health/sites/health/files/major_chronic_diseases/docs/2017_cancerscreening_2ndreportimplementation_en.pdf.

11. Wilt TJ, Harris RP, Qaseem A, et al. Screening for cancer: advice for high-value care from the American College of Physicians. Ann Intern Med. 2015;162(10):718-25.

12. Committee on Practice Guidelines G. Practice Bulletin No. 168: Cervical Cancer Screening and Prevention. Obstet Gynecol. 2016;128(4):e111-e30.

13. South Africa Department of Health Cervical Cancer Screening Programme. South Africa Department of Health Cervical Cancer Screening Programme. National Guidelines for Cervical Cancer Screening Programme [Available from: https://screening.iarc.fr/doc/SAcervical-cancer.pdf.

14. World Health Organization. World Health Organization. Cervical Cancer [Available from: https://www.who.int/cancer/prevention/diagnosis-screening/cervical-cancer/en/.

15. World Health Organization. World Health Organization. Guideline for screening and treatment of cervical pre-cancer lesions for cervical cancer prevention [Available from: https://www.who.int/publications/i/item/9789240030824.

16. UNAIDS. UNAIDS. Aidsinfo 2019 data [Available from: http://aidsinfo.unaids.org/.

17. Ramogola-Masire D, de Klerk R, Monare B, et al. Cervical cancer prevention in HIV-infected women using the "see and treat" approach in Botswana. J Acquir Immune Defic Syndr. 2012;59(3):308-13.

18. Haque MM RA, Dharma Hagare D, Chowdhury RK. A Comparative Assessment of Variable Selection Methods in Urban Water Demand Forecasting. Water. 2018;10.

19. Anderson J, Wysong M, Estep D, et al. Evaluation of Cervical Cancer Screening Programs in Cote d'Ivoire, Guyana, and Tanzania: Effect of HIV Status. PloS one. 2015;10(9):e0139242.

20. Msyamboza KP, Phiri T, Sichali W, et al. Cervical cancer screening uptake and challenges in Malawi from 2011 to 2015 : retrospective cohort study. BMC public health. 2016;16(1):806.

21. Denny L, Kuhn L, De Souza M, et al. Screen-and-treat approaches for cervical cancer prevention in low-resource settings: a randomized controlled trial. Jama. 2005;294(17):2173-81.

22. Kelly $\mathrm{H}$, Weiss HA, Benavente $\mathrm{Y}$, et al. Association of antiretroviral therapy with high-risk human papillomavirus, cervical intraepithelial neoplasia, and invasive cervical cancer in women living with HIV: a systematic review and meta-analysis. Lancet HIV. 2018;5(1):e45e58. 
23. Moscicki AB, Ellenberg JH, Crowley-Nowick P, et al. Risk of high-grade squamous intraepithelial lesion in HIV-infected adolescents. The Journal of infectious diseases. 2004;190(8):1413-21.

24. Parham GP, Mwanahamuntu MH, Kapambwe S, et al. Population-level scale-up of cervical cancer prevention services in a low-resource setting: development, implementation, and evaluation of the cervical cancer prevention program in Zambia. PloS one. 2015;10(4):e0122169.

25. Painter $\mathrm{H}$, Erlinger $\mathrm{A}$, Simon $\mathrm{B}$, et al. Impact of cervicitis on performance of cervical cancer screening using HRHPV testing and visual evaluation in women living with HIV in Botswana. International journal of gynaecology and obstetrics: the official organ of the International Federation of Gynaecology and Obstetrics. 2020.

26. Makhema J, Wirth KE, Pretorius Holme M, et al. Universal Testing, Expanded Treatment, and Incidence of HIV Infection in Botswana. The New England journal of medicine. 2019;381(3):230-42.

\section{Figures}

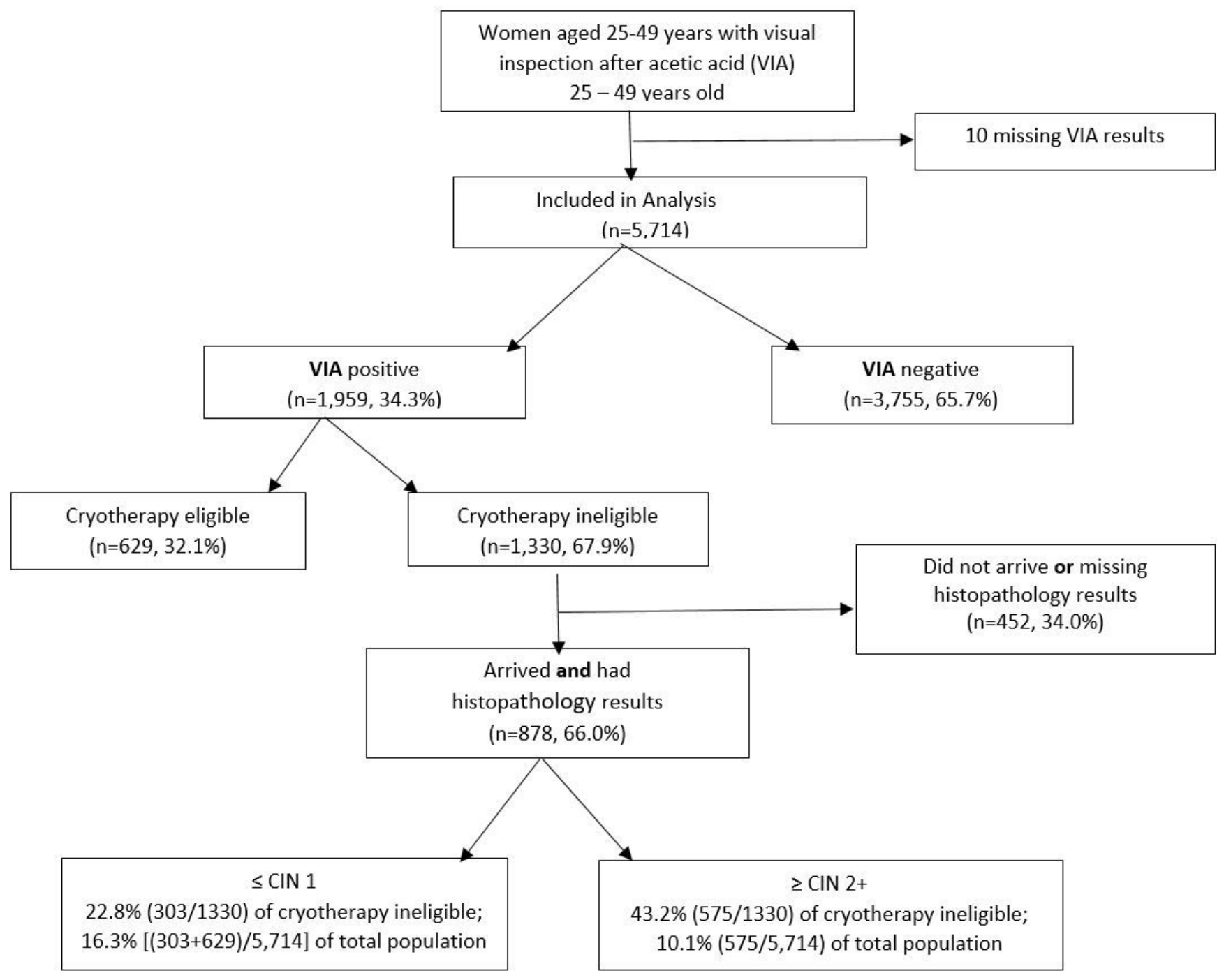

\section{Figure 1}

Study flow chart 